И. С. Тарбастаева. Теоретическая модель сохранения этнокультурного многообразия в республиках

УДК 353.2

DOI: 10.18101/1994-0866-2020-2-46-53

\title{
ТЕОРЕТИЧЕСКАЯ МОДЕЛЬ СОХРАНЕНИЯ ЭТНОКУЛЬТУРНОГО МНОГООБРАЗИЯ В РЕСПУБЛИКАХ
}

\author{
(C) Тарбастаева Инна Семеновна \\ младший научный сотрудник, \\ Институт философии и права СО РАН \\ Россия, 630090, г. Новосибирск, ул. Николаева, 8 \\ E-mail: inna-tarbastaeva@yandex.ru
}

В статье рассматриваются особенности сохранения этнокультурного и языкового многообразия в республиках в рамках реализации государственной национальной политики Российской Федерации. Показывается специфика культурных различий в республиках, заключающаяся в необходимости поддержания этносоциального баланса в институтах власти и управлении. В ходе исследования автором предлагается теоретическая модель сохранения этнокультурного многообразия в республиках, способствующая выработке институциональных механизмов согласования интересов этнических сообществ в системе региональной политики. Смысл модели состоит в поддержании этнического баланса в республике. Структурное измерение представленной модели реализуется в выделении следующих основных ее элементов: субъекты многообразия, предмет, цель сохранения этнокультурного многообразия, главные акторы и способы реализации. Исследование позволит дополнить научное знание в области разработки региональных моделей национальной политики.

Ключевые слова: национальная политика; этнокультурное многообразие; республики; этнический баланс; титульный этнос; русские; теоретическая модель; механизм реализации.

\section{Для цитирования}

Тарбастаева И. С. Теоретическая модель сохранения этнокультурного многообразия в республиках // Вестник Бурятского государственного университета. Философия.

2020. Вып. 2. С. 46-53.

\section{Введение}

Одними из главных задач в Стратегии государственной национальной политики Российской Федерации на период до 2025 года (далее - Стратегия) признаются сохранение и поддержка этнокультурного и языкового многообразия, которое определяется как «совокупность всех этнических культур и языков» ${ }^{1}$. Данная провозглашенная задача укладывается в общемировой тренд под эгидой ЮНЕСКО, ООН по сохранению богатого культурного многообразия. В национальных республиках ее реализация обусловлена особым публичноправовым статусом данных регионов, закрепленным в Конституции Российской Федерации. По замыслу Основного закона республики являются формой

${ }^{1}$ Стратегия государственной национальной политики Российской Федерации на период до 2025 года. Утверждена Указом Президента РФ от 19 декабря 2012 г. № 1666 // Официальный интернет-портал Президента РФ. Текст: электронный. URL: http://kremlin.ru/acts/bank/36512 (дата обращения: 24.08.2018). 
выражения права наций (народов) на самоопределение и сохранение своей этнокультурной самобытности, административное-территориальное разделение страны с учетом этнического фактора отражает сложившийся веками исторический опыт формирования Российского государства.

Цель настоящей статьи - сформулировать теоретическую модель сохранения этнокультурного многообразия в республиках. Актуальность данной модели обусловливается спецификой этнокультурного многообразия в республиках. Прежде всего тем, что этнокультурные потребности титульных этносов, давших название субъектам, в большей степени политизированы, чем в большинстве других регионов, где этничность граждан практически не влияет на их политическое поведение. В республиках национальность учитывается при распределении властных позиций [9], культурные различия институционализированы (этнические языки включены в образовательные стандарты). Титульные этносы «мыслят» республики как собственную территорию, родной дом, в котором установлены «свои» правила социального порядка. Республиканская идентичность экспертами выделяется как особый вид региональной идентичности, основанной на самоидентификации населения республик со своим административным регионом с точки зрения «близости и реальности ее восприятия, традиционности ее воображения, большей легкости ее конструирования» [2, с. 52]. Все это служит основанием для выделения республик в качестве особых регионов, где проблема сохранения этнокультурного многообразия носит свою специфику, а также достаточным условием для осмысления и разработки теоретической модели, направленной на решение этой задачи.

\section{Обзор литературы}

Специалисты в области межнациональных отношений обращаются к проблеме формирования дифференцированного подхода в управлении, учитывающего региональные особенности. Серьезной разработкой региональных моделей национальной политики занимается научный коллектив новосибирской этносоциологической школы при Институте философии и права СО РАН. В 2016 г. вышла в свет коллективная монография «Региональные модели государственной национальной политики современной России» под редакцией Ю. В. Попкова [10]. Авторы анализируют региональные модели в Республики Бурятия (В. Г. Костюк), Республики Саха (Якутия) (М. А. Абрамова), Республики Алтай (С. А. Мадюкова, О. А. Персидская).

Отдельно стоит отметить значительный вклад в разработку региональных моделей Дальнего Востока исследовательницы Е. Г. Маклашевой [4]. Она полагает, что регионы достаточно адаптивно и избирательно выстраивают вектор национальной политики сообразно особенностям этнополитических процессах на конкретных территориях. Анализируют проблему проведения национальной политики в приграничных регионах С. Г. Максимова, А. Г. Морковкина [5]. Ранее мной также осмыслялись особенности национальной политики в Республике Тыва в период 1991-2016 гг. [12; 13]. Между тем вышеописанные модели во многом отталкиваются от ситуации в конкретных регионах. Опираясь на богатый эмпирический материал, исследователи описывают сложившиеся практики управления на местах, их соотношение с федеральными ориентирами. Представляется значимым для научного социального знания выделение 
И. С. Тарбастаева. Теоретическая модель сохранения этнокультурного многообразия в республиках

теоретической модели применительно к конкретной государственной задаче сохранению этнокультурного многообразия в республиках. В представленной модели реализуется определенный концептуальный подход к этнокультурному многообразию, который заключается в том, что первичными носителями многообразия являются прежде всего этнические сообщества. Именно в них аккумулируются устойчивые практики взаимодействия, составляющие ключевое звено этнической культуры. Отдельный индивид выражает лишь определенный срез этнокультурного бытия, следовательно, сохранение культуры предполагает обеспечение поддержки коллективных форм существования этничности в виде этнических сообществ [11].

\section{Особенности этнокультурного многообразия в республиках}

Российские республики имеют ряд особенностей, в отличие от других административно-территориальных субъектов они вправе принимать конституции, устанавливать государственные языки и использовать их в органах государственной власти, органах местного самоуправления, государственных учреждениях республики наряду с русским языком (согласно ст. 66, 68 Конституции РФ). Несмотря на равные политико-правовые полномочия, как показывают данные Всероссийской переписи населения 2010 г., современные республики представляют собой достаточно разноликие субъекты ${ }^{1}$. В период с 2002 по 2010 г. изменялась численность титульных этносов, имеющих национальные республики. Наиболее удачно классификацию республик в зависимости от гетерогенности и конфигурации доли титульной группы и русского населения представили П. В. Панов, Е. Ю. Филиппова [9] (табл. 1).

Типология российских республик в зависимости

Таблица 1 от этнической структуры населения [9]

\begin{tabular}{|c|l|l|l|}
\hline № & \multicolumn{1}{|c|}{ Республики } & \multicolumn{1}{|c|}{$\begin{array}{c}\text { Соотношение } \\
\text { титульного и русского } \\
\text { населения }\end{array}$} & \multicolumn{1}{|c|}{ Наименование региона } \\
\hline 1 & $\begin{array}{l}\text { с явным } \\
\text { доминированием } \\
\text { титульного } \\
\text { населения }\end{array}$ & $\begin{array}{l}\text { Доля титульного } \\
\text { населения более } 80 \%\end{array}$ & Ингушетия, Тыва, Чечня \\
\hline 2 & $\begin{array}{l}\text { с явным } \\
\text { доминированием } \\
\text { русского } \\
\text { населения }\end{array}$ & $\begin{array}{l}\text { Доля русского } \\
\text { населения более } 80 \%\end{array}$ & Карелия, Хакасия \\
\hline 3 & $\begin{array}{l}\text { русские явно } \\
\text { преобладают в } \\
\text { составе населения }\end{array}$ & $\begin{array}{l}\text { Доля русского } \\
\text { населения от 50 до }\end{array}$ & $\begin{array}{l}\text { Адыгея, Алтай, Бурятия, Коми, } \\
\text { Удмртия }\end{array}$ \\
\hline
\end{tabular}

\footnotetext{
${ }^{1}$ Всероссийская перепись населения 2010 года. Официальные итоги с расширенными перечнями по национальному составу населения и по регионам // Федеральная служба государственной статистики: сайт. Текст: электронный. URL: http://www.gks.ru/free_doc/new_ site/perepis2010/croc/results2.html (дата обращения: 01.02.2020).
} 


\begin{tabular}{|l|l|l|l|}
\hline 4 & $\begin{array}{l}\text { титульная группа } \\
\text { явно преобладает в } \\
\text { составе населения }\end{array}$ & $\begin{array}{l}\text { Доля титульного } \\
\text { населения от 50 до } \\
65 \%\end{array}$ & $\begin{array}{l}\text { Калмыкия, Саха (Якутия), Северная } \\
\text { Осетия - Алания, Татарстан, } \\
\text { Чувашия }\end{array}$ \\
\hline 5 & $\begin{array}{l}\text { примерное } \\
\text { равенство русского } \\
\text { и титульного } \\
\text { населения }\end{array}$ & $\begin{array}{l}\text { Примерно 50\% на } \\
50 \%\end{array}$ & Марий Эл, Мордовия \\
\hline 6 & $\begin{array}{l}\text { полиэтническая } \\
\text { структурой } \\
\text { населения }\end{array}$ & & $\begin{array}{l}\text { Башкортостан, } \\
\text { Кабардино-Балкарская Республика, } \\
\text { Карачаево-Черкесская Республика }\end{array}$ \\
\hline
\end{tabular}

Как мы видим, степень полиэтничности в республиках значительно разнится: удельный вес титульного этноса в структуре населения может варьироваться от 12 (Хакасия) до $80 \%$ (Тува). Чем выше доля титульного этноса, отмечает М. В. Назукина, тем выше степень значения этнических маркеров идентичности республики [6, с. 713]. В моноэтничных регионах наблюдается высокий социальный статус группы, давшей название субъекту, а этнический фактор воспринимается в обществе как политически значимый. Так, в северокавказских республиках реализуется модель power-sharing, когда распределение ключевых должностей производится в соответствии с этнической структурой общества. По оценкам экспертов, это позволяет поддерживать баланс в межэтнических отношениях [9]. Также в республиках с гетерогенным этническим составом чаще наблюдается клановость, которая понижает эффективность управленческого потенциала, формирует отрицательный имидж власти у населения. В то время как в республиках с доминирующей долей русского населения титульная группа зачастую выполняет роль этнокультурного своеобразия, «изюминки» в общем этносоциальном ландшафте, а фактически управление межнациональными отношениями мало чем отличается от других регионов России (Карелия).

Баланс интересов при сохранении этнокультурного многообразия

Сложности управления культурными различиями в республиках обусловлены необходимостью поддержания баланса интересов между титульной группой и прежде всего русским населением, от социального самочувствия которого во многом зависит этнополитическая стабильность в регионе. В последние годы наиболее отчетливо проявляется позиция федеральной власти по «деполитизации этнической идентичности, значение которой главным образом переносится в культурную плоскость» [1, с. 7].

Наглядным примером этого является ситуация по изучению родных языков в сфере образования. Известно, что русское население в ряде республик выступило против обязательного изучения этнических языков, мотивируя сокращением часов по русскому языку, который обязателен для сдачи ЕГЭ и во многом определяет успешное поступление в высшее учебное заведение. Президент Российский Федерации

\footnotetext{
${ }^{1}$ По оценкам П. В. Панова, Е. Ю. Филипповой, здесь выделяется несколько (более двух) крупных этнических сегментов, причем ни один из них не является большинством населения (исключение: кабардинцы в Кабардино-Балкарской Республике).
} 
И. С. Тарбастаева. Теоретическая модель сохранения этнокультурного многообразия в республиках

поддержал их позицию, заявив, что принуждать человека изучать язык, который для него не является родным, недопустимо ${ }^{1}$. Вскоре Федеральным законом от 3 августа 2018 года № 317 Ф3 были внесены поправки: преподавание и изучение государственных языков республик осуществляется добровольно и не в ущерб преподаванию и изучению государственного языка Российской Федерации ${ }^{2}$. Кроме того, русский язык был включен в перечень родных языков и теперь может быть свободно выбран, вне зависимости от национальной принадлежности. В результате этих решений в 2018-2019 гг. около 10\% (всего 7 учеников) школьников Марий Эл выбрали марийский язык для изучения в качестве родного. Башкирский язык выбрали $15,6 \%$, татарский - 9,45\% ${ }^{3}$. Верно отмечают В. Б. Евдокимов, Т. В. Ашиткова, что «миллионы российских граждан при отсутствии прямого запрета на изучение родных языков поставлены в объективные условия, вынуждающие отказываться от их изучения в школах» [3, с. 89].

В стратегических ориентирах и тактических решениях федеральной власти виден постепенный отказ от спонсирования культурных отличий. Тому подтверждение - сужение правотворческой деятельности республик в сфере образования, что приводит к размыванию статуса государственных языков в национальных республиках [8].

Одновременно с этим наблюдается усиление внимания центра к социальному положению русского населения в республиках. В 2018 г. в Стратегию были внесены изменения, в частности в качестве актуальной проблемы национальной политики был признан «отток русского и русскоязычного населения из регионов Северного Кавказа, Сибири и Дальнего Востока страны» ${ }^{4}$. Действительно, экспертами зафиксирована миграционная убыль русских в северокавказских республиках, Саха (Якутии), Туве и других республиках одновременно с естественным приростом титульного населения, что позволяет говорить о сокращении этнокультурного многообразия в данных регионах. Эта поправка вполне оправдана, поскольку присутствие русских, их социальное благополучие в национальных субъектах важны с точки зрения гражданской консолидации российской нации, снижения геополитических рисков в приграничных республиках. При этом пока остается неясным, как власти планируют остановить

\footnotetext{
${ }^{1}$ Родной язык станет сугубо родительским // Коммерсантъ. 2018. № 64. 13 апр. Текст: электронный. URL: www.kommersant.ru (дата обращения: 13.02.2020).

${ }^{2} \mathrm{O}$ внесении изменений в статьи 11 и 14 Федерального закона «Об образовании в Российской Федерации» Федеральный закон от 03.08.2018 № 317-Ф3. Доступ из справочно-правовой системы КонсультантПлюс. Текст: электронный. URL: http://www.consultant.ru/ document/cons_doc_LAW_304090/ (дата обращения: 13.02.2020).

${ }^{3}$ Медиа-проект Гильдии межэтнической журналистики // Национальный акцент. Текст: электронный. URL: https://nazaccent.ru (дата обращения: 04.02.2020).

${ }^{4} \mathrm{O}$ внесении изменений в Стратегию государственной национальной политики Российской Федерации на период до 2025 года, утвержденную Указом Президента Российской Федерации от 19 декабря 2012 г. № 1666: указ Президента Российской Федерации // Информационно-правовой портал «Гарант.ру». Текст: электронный. URL: http://base.garant.ru/70284810/ (дата обращения: 13.02.2020).
} 
«сжатие» русского населения; нет прямых руководств к действию, разработанных комплексных программ.

Несмотря на сложности управления культурными различиями в республиках, надо отметить, что они выполняют значимую общественно-политическую функцию - предотвращают ассимиляцию и способствуют сохранению этнокультурной самобытности народов. Их ликвидация в рамках проекта укрупнения регионов ${ }^{5}$ нанесет существенный ущерб культуре, традициям, языкам, прежде всего, титульных этносов.

\section{Теоретическая модель сохранения этнокультурного многообразия}

Потребность в теоретической модели сохранения этнокультурного многообразия в национальных республиках продиктована необходимостью создания институциональных механизмов согласования интересов разных сообществ в системе региональной политики. Смысл модели состоит в поддержании этнического баланса в республике. Структура модели может быть представлена в основных элементах следующим образом.

Субъекты многообразия - этнические сообщества, в которых аккумулируются социальные и культурные практики.

Предмет - этнокультурные и этносоциальные потребности индивидов, составляющих этническое сообщество.

Цель сохранения этнокультурного многообразия заключается в фактическом сохранении титульных этносов и языков, и бесконфликтном взаимодействии этнических сообществ. Особое внимание в моноэтнизирующихся республиках следует уделить русскому населению. Другими словами, цель сохранения этнокультурного многообразия заключается в межнациональном мире и согласии по основным вопросам социального устройства региона. Подчеркну, что фактическое сохранение титульных этносов, носителей языков, также крайне важно. Согласно данным ЮНЕСКО, в России под угрозой исчезновения находятся 136 языков. Приближаются к исчезновению удмуртский, калмыцкий, под угрозой находятся якутский, тувинский. Несмотря на то, что общая численность чеченцев, осетин, якутов, бурятов, алтайцев, ингушей, алтайцев, черкесов за период между переписями выросла, динамика владения языком титульной национальности во всех республиках отрицательная, за исключением Тувы [8].

Главные акторы сохранения этнокультурного многообразия - это региональные органы власти. Следует подчеркнуть, что региональным властям не нужно ждать с низов запроса на поддержание культурной самобытности, а проявлять инициативу сверху. В настоящее время в республиках работа органов власти выстроена по большей части на взаимодействии с общественными организациями, чья деятельность за редким исключением ограничивается проведением фестивалей, праздников.

\footnotetext{
${ }^{5}$ В 2005 г. ликвидирован Коми-Пермяцкий национальный округ, в 2007 — Таймырский, Корякский и Эвенкийский автономный округа, в $2008-$ Усть-Ордынский Бурятский и Агинский Бурятский автономные округа.
} 
И. С. Тарбастаева. Теоретическая модель сохранения этнокультурного многообразия в республиках

Механизм реализации заключается в преодолении ассимиляционных процессов в отношении титульных этносов, а также остановке оттока русского и русскогоязычного населения из республик Северного Кавказа, Сибири и Дальнего Востока.

Способ реализациии - а) программно-целевой метод (межведомственные программы); б) включение региональных органов власти в неформальные практики взаимодействия, самоорганизации этнических сообществ на местах. Использование программно-целевого подхода позволяет системно подходить к проблемам, вовлекать в социальное управление институты гражданского общества, но в то же время эксперты по национальной политике отмечают «слабое ресурсное сопровождение программ, недостаточность финансирования, несовершенство технологий реализации» [7, с. 744]. Региональным властям следует проявлять гибкость в подходе к управлению межнациональными отношениями, не бояться отходить от формальных процедурных мер, а включаться в реальные практики социальных взаимоотношений путем принятия нестандартных решений. Находить возможности для поддержания этнического баланса, сохраняя этнокультурное многообразие.

Таким образом, в представленной теоретической модели фиксируются главные элементы, влияющие на гармонизацию межэтнических отношений в республиках. Фактически существуют две неблагоприятные тенденции, свидетельствующие о сокращении этнокультурного многообразия в национальных субъектах: сокращение русского и русскоязычного населения путем миграции либо уменьшение численности титульных групп в следствии ассимиляции или демографического спада рождаемости. Признавая, что причины оттока русских, включающие поиск лучших социальноэкономических условий для жизни, часто носят комплексный характер. Стоит отметить, что межэтническая напряженность в локальном сообществе также служит дополнительным фактором, способствующим миграции. И в этом смысле под сохранением этнокультурного многообразия в республиках следует также иметь в виду сохранение присутствия русского населения как стабилизирующего условия в гражданском и геополитическом контекстах. Также при сохранении многообразия в национальных субъектах принципиально важным представляется учет этнического баланса в общественных отношениях. Дальнейшая разработка представленной модели может найти свое применение в конкретных практиках управления.

\section{Литература}

1. Адиев А. 3. Представительство этнических групп в органах власти как фактор социально-политической стабильности на Северном Кавказе // Ойкумена. Регионоведческие исследования. 2018. № 4. С. 7-16.

2. Дробижева Л. М. Российская, этническая и республиканская идентичность // Центр и региональные идентичности в России / под ред. В. Гельмана и Т. Хопфа. СПб.: Изд-во Европ. ун-та в СПб.; Летний сад, 2003. С. 47-76.

3. Евдокимов В. Б., Ашиткова Т. В. О некоторых проблемах государственных языков в субъектах Российской Федерации // Вестн. Том. гос. ун-та. Право. 2019. № 33. С. 83-95.

4. Маклашова Е. Г. Управленческие акценты региональных программ по реализации национальной политики (на примере Дальнего Востока) // Регионология. 2017. № 4(101). C. 512-533.

5. Максимова С. Г., Морковкина А. Г. Эффективность реализации государственной национальной политики в приграничных регионах России // Вестник АГАУ. 2016. № 11(145). С. 178-183. 
6. Назукина М. В. Маркеры этничности в региональной идентичности республик России // Регионология. 2018. № 4(105). С. 698-717.

7. Напалкова И. Г., Солдатова А. С., Курочкина К. В. Специфика развития этнонационального пространства современной России как фактор нациестроительства: стратегический ситуационный анализ // Регионология. 2019. Т. 27, № 4. С. 734-756.

8. Одинг Н. Ю., Юшков А. О., Савулькин Л. И. Использование национальных языков как государственных в республиках РФ: правовые и экономические аспекты // Пространство экономики. 2019. № 1. С. 112-130.

9. Панова П. В., Филиппова Ю. Е. Практики распределения властных позиций в российских «национальных республиках»: проблема межэтнического баланса // Вестник Пермского университета. Политология. 2015. № 3. С. 33-47.

10. Региональные модели государственной национальной политики современной России: в 2 ч. / М. А. Абрамова [и др.]; под ред. Ю. В. Попкова; ИФПР СО РАН. Новосибирск: Манускрипт, 2016. Ч. І. 176 с.

11. Тарбастаева И. С. Коллективные права этнических общностей: к проблеме правосубъектности в этнонациональной политике // Знание. Понимание. Умение. 2015. № 4. C. 101-107.

12. Тарбастаева И. С. Правовое поле этнонациональной политики в Республике Тыва (1991 - наст. вр.) // Новые исследования Тувы. 2016. № 2. Текст: электронный. URL: http://nit.tuva.asia/nit/article/view/98 (дата обращения: 10.04.2020).

13. Тарбастаева И. С. Региональные модели национальной политики в Республике Тыва: 1991-2016 гг. // Региональная политика - 2016: сборник статей и аналитических докладов / под ред. Д. Орлова. М.: Грифон, 2017. С. 297-306.

\section{A THEORETICAL MODEL FOR THE PRESERVATION OF ETHNOCULTURAL DIVERSITY IN REPUBLICS}

Inna S. Tarbastaeva

Junior Researcher,

Institute of Philosophy and Law SB RAS

8 Nikolaeva St., Novosibirsk 630090, Russia

E-mail: inna-tarbastaeva@yandex.ru

The article discusses the peculiarities of preserving ethnocultural and linguistic diversity in republics as a part of the implementation of the state national policy in the Russian Federation. We have emphasized the specificity of cultural differences in republics, which make necessary the maintaining of ethnosocial balance in the institutions of power and administration. During the study, we propose a theoretical model for the preservation of ethnic and cultural diversity in republics, which is aimed at the development of institutional mechanisms for harmonizing the interests of ethnic communities in the regional policy system. A model is meant for maintainance of the ethnic balance in the republic. The structure of the presented model includes the following main elements: subjects of diversity, an object, a purpose of preserving ethnocultural diversity, main actors and methods of implementation. The study will complement scientific knowledge in the development of regional models of national policy.

Keywords: national policy; ethnocultural diversity; republics; ethnic balance; titular ethnic group; Russians; a theoretical model; implementation arrangements. 